\title{
Influence of the stolon/soil surface interface and plant morphology on the survival of white clover during severe drought
}

\author{
J.L. BROCK and MOON CHUL KIM \\ AgResearch Grasslands, Private Bag, Palmerston North, New Zealand \\ Department of Animal Science, Cheju National University, Cheju, Korea
}

\section{Abstract}

Field observations indicate that conditions at the stolon/soil surface interface are important for the survival of white clover (Trifolium repens) during drought. Mini-swards of clonal material of two contrasting white clover cultivars (Grasslands Tahora, small-leaved, densely branched; Dusi, large-leaved, tap-rooted) were established in boxes (300 × $420 \times 290 \mathrm{~mm}$ deep) for 6 months, then subjected to a 6-week drought. Stolon/soil surface conditions were modified to have stolons either, 1) fully exposed, 2) shaded, or 3) buried. Numbers and, characteristics of surviving plants were measured. The major effect was on the number of plants surviving. More plants survived under shading $(55 \%)$ than burial $(25 \%)$ and full exposure $(17 \%)$. Numbers of plants surviving drought was related to pre-drought plant density, hence Tahora had higher plant survival than Dusi, particularly when fully exposed. Although initially Dusi plants were 25 times heavier, with 5 times the number of stolons ${ }^{-}$and $^{-}$roots- of-Tahora-surviving-plants-of both cultivars were small and similar in dry weight, although Tahora had higher numbers of growing points and roots thanDusi. The tap-rooted character of Dusi did not. confer any advantage during drought. It was concluded that the main factor influencing drought survival of white clover appears to be grazing management. Systems that can produce dense white clover populations and maintain high pasture density (grass) capable of providing shelter from direct solar radiation during drought stress, are superior.

K eywords: drought survival, plant density, plant morphology, stolon burial, stolon shading, Trifolium repens

\section{Introduction}

Depending on severity, drought can cause large scale loss of both current and long-term production from white clover (Trifolium repens) in pastures. Initially, as wilting approaches, leaves die and current production is reduced as the stolon adjusts osmotically to survive at the expense of leaf growth (Turner 1990, 1991). As severity of the drought increases, stolons tend to die back to strongly rooted nodes, and the frequency of plant death increases, resulting in a decline in population density and long-term losses. These effects are more severe if the drought occurs early in the season (Brock 1988), when plants are still small and recovering from their normal mid-spring fragmentation (Brock et al. 1988). For instance, in Canterbury, Vartha \& Hoglund (1983) reported a 30\% loss of white clover production from a summer drought (January-February), but a $50 \%$ loss from a spring drought (October) in two consecutive seasons. Again, a 6-week drought in late spring-early summer (November-December) in the Manawatu, (Brock 1988) caused a 70\% loss in production and a $85 \%$ loss of stolon material in a rotationally grazed pasture which subsequently took 3 years to recover, but by contrast, in continuously set stocked pastures the white clover was largely unaffected (apart from loss of leaf), with immediate recovery following rain. Differences in pasture architecture affecting the microenvironment of stolons were thought to be responsible for this.management effect. High pasture cover produced by set stocking intercepted direct solar radiation, shading stolons and cooling the soil surface $\left(40^{\circ} \mathrm{C}\right)$, whereas the low density rotationally grazed pastures, with the large areas of bare soil exposed after grazing, resulted in higher soil surface temperatures $\left(50^{\circ} \mathrm{C}\right)$ and high stolon death. Under rotational grazing, surviving clover plants were associated with the shelter of large grass clumps (Brock \& Hay 1993).

In order to quantify some of these observations apd better define the environmental factors and plant characteristics at- the stolon/soil surface. interface important for the survival of white clover subjected to drought, a box-scale experiment was used, in order to provide sufficient soil surface and volume to simulate field conditions.

\section{$M$ aterials and methods}

Soil surface/stolon interface treatments included in the experimental design were stolon burial, as much of white clover stolon material is normally buried, varying between $90 \%$ in winter/early spring to $50 \%$ in summer (Hay et al. 1983), and shading of the soil surface to 
reduce soil surface temperatures and the heat load on white clover stolons. Variation in plant morphology may also affect drought survival, and two contrasting cultivars, Grasslands Tahora (a small-leaved sioloniferous type with thin stolons and fibrous root system), and Dusi (a large-leaved type, with thick stolons and pronounced tap-root development) (Caradus 1986) were included.

\section{Experimental treatments}

The following treatments were incorporated into the $2 \mathrm{x}$ 4 fully randomised block design with 3 replications.

A. Soil moisture/surface conditions.

1. Fully surface watered, stolons exposed.

2. No water for 6 weeks, stolons exposed.

3. No water for 6 weeks, stolons shaded.

4. No water for 6 weeks, stolons buried.

B. Plant morphology

1. Grasslands Tahora white clover.

2. Dusi white clover.

\section{Procedures}

The boxes were constructed from $12 \mathrm{~mm}$ treated plywood $(300 \times 400 \times 230 \mathrm{~mm})$, lined with polyethelene film and screwed to a plastic planter tray (60 $\mathrm{mm}$ deep) base and filled with a Pongakawa peaty loam, a freedraining, low-fertility soil of volcanic origin from Waiouru in the central North Island. After collection from the field, the soil was sieved and packed evenly into the boxes in layers to achieve a bulk density of 0.75 . Fertiliser (P, K and Mo) was added to the top $50 \mathrm{~mm}$ of soil at rates equivalent to 100,50 and $0.02 \mathrm{~kg} /$ ha respectively, to maintain strong clover growth.

On 28 May 1990, all boxes were planted with 10 rooted tip cuttings of clonal material propagated from one genotype of either Tahora or Dusi to eliminate genotypic variation. During the next 6 months (commencing on 12 July 1990) all boxes were placed in a heated glasshouse (minimum $15^{\circ} \mathrm{C}$ ), watered 3 times a week, and cut to $1 \mathrm{~cm}$ at approximately 3-week intervals $(7 \mathrm{cuts})$. The surface of the stolon burial treatment was covered with $5 \mathrm{~mm}$ of soil after cuts 2 and 5 .

Rate of establishment of the two cultivars was greatly different. Tahora, through rapid stolon extension and branching, had completely colonised the surface area of the boxes by the third cut, and by cut 5 was undergoing stolon death and plant fragmentation as normally found in the field (Brock et al. 1988). By contrast, Dusi took the full 6 months to fully coionise the soil surface without significant fragmentation occurring. As a consequence, the populations of the two cultivars at the start of the drought treatment were quite different, Tahora consisting of small, sparsely branched plants, and Dusi of larger, more complex plants.

Following the last cut (27 November 1990) the experiment was transferred to sand frames outside and $5 \mathrm{~mm}$ of pumice applied to the surface of the shaded treatment. On 3 December 1990, drought treatments were imposed and continued for 6 weeks. The fully watered treatment was watered 3 times a week. Whenever rain threatened during the experimental drought period, all boxes were covered by large frames covered with clear polyethelene film suspended $1 \mathrm{~m}$ above the ground to intercept ram but allow natural air movement. A final herbage cut on all boxes was made on 22 December 1990, as the soil approached 40\% total water content (approx. 15\% available water) as determined by weighing,'

On 15 January 1991, all boxes were watered to full capacity and 'plants of the fully watered treatment harvested and measured. Droughted 'treatments were allowed a further 2 weeks for surviving plants to recover sufficiently to be recognised by the production of new leaves, but before the formation of new buds and stolon growth could commence. Boxes were emptied by inverting, then the soil mass gently washed away and all the plants collected intact and counted. A maximum of 14 plants were taken at random from each box for detailed measurement. Each plant was classified according to their complexity of branching, plants with a single unbranched stolon were classified as 1 St-order, those with a single hierarchy of branching as 2nd-order, those with two hierarchies as 3rd-order, and so on (Brock et al. 1988). Numbers of leaves, flowerheads (watered treatments only), growing points, stolons, fibrous (adventitious) roots and tap-roots, and total length of stolon were recorded. Total leaf, flowerhead, stolon, fibrous root and tap-root dry weight (DW) were determined. A tap-root was defined as a root with a diameter $\geq$ half the diameter of the stolon at its point of junction.

Analysis of variance was conducted on all data presented. Characteristics of plants from the fully watered treatment and those surviving the three droughted treatments were analysed separately, as the distribution of the data was not normal. when all treatments were combined.

\section{Results}

\section{Herbage growth and plant survival}

After 3 weeks of drought, growth was reduced in all drying treatments compared with the fully watered treatment, with the reduction of greater significance for Tahora (Table 1). Lowest values were from the buried stolon treatment, and stolon shading increased herbage 
growth compared to fully exposed stolons for Tahora, but not Dusi. There was no further significant herbage production as subsequent leaves rapidly wilted and died.

Tahora had considerably more plants surviving in all dry treatments than Dusi, with greater survival in the shaded treatment compared to the exposed and buried stolon treatments.

\section{Plant characteristics}

The difference in the populations between the two cultivars is reflected in the large difference in the size and complexity of plants in the fully watered treatment, Dusi having 5 times more stolons and 20 times the weight of Tahora plants. Only in the number of leaves/ growing point was Tahora greater than Dusi (3.1 and 2.5 respectively).

All plants surviving the drought treatments were small and simple in structure (only 1st- and 2nd-order plants). The effect of stolon treatments in reducing the severity of drought on plants was generally in the order of burial $\geq$ shaded $>$ exposed stolons, with Tahora generally greater in numbers and length of components, but Dusi heavier. Interactions between stolon treatment and cultivar indicated that Dusi was more adversely affected than Tahora where stolons were exposed on the soil surface, particularly in number of roots and growing points, stolon length and DW.

\section{Discussion}

During the drying-down phase of the drought before growth ceased, Tahora leaf production was more affected by the drought treatments than Dusi, except where the soil surface was shaded, whereas Dusi remained relatively unaffected. This could be attributed to either, differences in stolon morphology (smaller, thinner stolons of Tahora being more sensitive to heat stress than the thicker stolons of Dusi), or genetic background induced by differences in environment (cool-temperate New Zealand hill-country opposed to hot, dry South African conditions). While some new leaf production continued after cutting, leaf death was high as the drought intensified and plant survival became the issue. This reflects the ability of white clover stolons to adjust osmotically to survive at the expense of leaf growth (Turner 1990, 1991).

The major effect of drought was on the numbers of plants surviving. Protection of stolons at the soil surface was critical to survival. Shading, by interception of direct solar radiation reduces temperature at the stolon/ soil surface (Brock \& Hay 1993), and was the most successful in maintaining survivor numbers. Stolon burial was partially successful as only the older portion of the stolon was protected from direct radiation by burial, with the younger active stolon exposed on soil

Table 1 Mean herbage yields (g DW/box) after 3 weeks drought, number of surviving plants/sox and their chāracteristics after 6 weeks of drought (values in parentheses are the $\%$ of plants with that character).

\begin{tabular}{|c|c|c|c|c|c|c|c|c|c|}
\hline & Tahora & $\begin{array}{r}\text { water--- } \\
\text { Dusi }\end{array}$ & $\begin{array}{l}\text {--Exposed } \\
\text { Tahora }\end{array}$ & $\begin{array}{l}\text { stolons-- } \\
\text { Dusi }\end{array}$ & $\begin{array}{l}\text {--Shaded } \\
\text { Tahora }\end{array}$ & $\begin{array}{l}\text { stolons.*. } \\
\text { Dusi }\end{array}$ & $\begin{array}{l}\text {---Buried } \\
\text { Tahora }\end{array}$ & $\begin{array}{c}\text { stolons-- } \\
\text { Dusi }\end{array}$ & $\begin{array}{l}\text { Signif." } \\
(P<0.05)\end{array}$ \\
\hline Herbage yield (g DW/box) & 4.98 & 12.72 & 1.84 & 7.96 & 3.01 & 7.65 & 1.07 & 6.59 & C, ST \\
\hline Surviving plants (numbers/box) & 125 & 40 & 32 & 2 & a3 & 19 & 38 & 9 & $\mathrm{C}, \mathrm{ST}$ \\
\hline Characteristics: Stolon & & & & & & & & & \\
\hline Plant order & 1.65 & 2.45 & 1.76 & 1.26 & 1.70 & 1.60 & I .a3 & 1.54 & C \\
\hline Growing point number & 2.27 & 13.53 & 1.64 & 0.69 & 1.70 & 1.57 & 1.78 & 0.53 & $\mathrm{C} \times \mathrm{ST}$ \\
\hline Total stolon number & 2.56 & 14.20 & 2.21 & 1.12 & 2.30 & 2.34 & 2.60 & 1.95 & ns \\
\hline Total-stolon length (mm) & 60.3 & 515.1 & 25.7 & 3.0 & 42.4 & 32.0 & 52.2 & 39.9 & C, ST \\
\hline Specific stolon length (mm/mg) & 3.57 & 1.60 & 2.57 & 1.40 & 3.23 & 1.49 & 2.61 & 1.20 & $\mathrm{C}_{1} \mathrm{ST}$ \\
\hline Stolon DW (mg) & 16.9 & 431.4 & 10.2 & 7.6 & 14.8 & 24.8 & 21.2 & 43.8 & C. ST \\
\hline \multicolumn{10}{|l|}{ Roots } \\
\hline Number of tap-roots & $1.3(76)$ & 10.6 (91) & $1.4(93)$ & $1.1(58)$ & $1.9(88)$ & $1.7(94)$ & $1.6(83)$ & $2.4(96)$ & $\mathrm{C} \times \mathrm{ST}(\mathrm{ns})$ \\
\hline Number of fibrous roots & 5.9 (97) & $32.6 \quad(100)$ & $3.4(79)$ & $0.3(17)$ & 3.8 (a) & $2.7(63)$ & $6.5(93)$ & 2.8 (45) & C. ST (C) \\
\hline Total number of roots" & 6.78 & 43.26 & 3.87 & 0.77 & 4.81 & 3.30 & 7.37 & 3.76 & C, ST \\
\hline Tap-root:fibrous root ratio & 0.20 & 0.20 & 0.60 & 0.64 & 0.39 & 0.63 & 0.24 & 0.71 & $\mathrm{C} \times \mathrm{ST}$ \\
\hline Tap-root DW (mg) & 20.7 & 311.5 & 13.9 & 21.7 & 13.5 & 24.4 & 17.8 & 44.2 & $\mathrm{C}, \mathrm{ST}$ \\
\hline Fibrous root DW (mg) & a.4 & 193.4 & 2.0 & 1.0 & 3.3 & a.9 & 5.2 & 12.8 & ns \\
\hline Total root DW $(\mathrm{mg})^{* *}$ & 18.9 & 463.9 & 14.8 & 16.8 & 14.0 & 28.6 & 20.2 & 48.6 & $\mathrm{C}, \mathrm{ST}$ \\
\hline Total DW $(\mathrm{mg})^{* *}$ & 69.9 & 1476.3 & 40.6 & 29.5 & 46.0 & 67.0 & 70.9 & 98.5 & ST \\
\hline Stolon:rool DW ratio & 1.20 & 1.01 & 0.76 & 0.78 & 1.69 & 1.20 & 1.21 & 1.26 & ns \\
\hline
\end{tabular}

$\mathrm{C}=$ cultivar, $\mathrm{ST}=$ stolon treatment, $\mathrm{ns}=$ not significant et $\mathrm{P}<0.05$

"Data for totals weighted for proportion of plants with each root type, and includes leaf for watered treatment. 
surface. Dusi was more adversely affected than Tahora suggesting that stolon morphological characteristics (high node density, high branching, thin stolons) are more important factors in drought survival than root characteristics or the background environment in which they were developed. Then again, it may also be a function of plant density, with a higher pre-drought density ensuring greater post-drought survival, as the proportion of the plants surviving was similar for both cultivars under shading (Tahora 65\%, Dusi 50\%) and burial (Tahora 30\%, Dusi 23\%), but not full exposure (Tahora 25\%. Dusi 5\%).

The density of plants normally found in grass/clover pastures ranges from 330 to $550 / \mathrm{m}^{2}$ (Hay et al. 1989). With corresponding numbers of surviving plants being 690 and $160 / \mathrm{m}^{2}$ for Tahora and Dusi respectively under shading, 320 and $75 / \mathrm{m}^{2}$ under burial, and 270 and $16 /$ $\mathrm{m}^{2}$ for bare soil, Tahora would have sufficient plants to ensure recovery, whereas Dusi may not, particularly in bare soil.

Taking the characteristics of plants from the watered treatment as indicative of plant condition before the drought, indicated that complexity and size of predrought plants conferred no advantage for plant survival under severe drought conditions. All surviving plants were small, being similar in size to first-order Huia plants in normal plant populations (Brock et al. 1988). Drought had little effect on the size and structure of surviving Tahora plants, already small before the drought. By contrast, the large Dusi plants with features such as thicker stolons and larger tap-roots, were severely affected, particularly when fully exposed to direct solar radiation, suffering a 98\% loss in stolon DW. This would suggest that small plants are better able to withstand drought, possibly through having less biomass (stolon) to support. The effects of stolon protection by burial or shading on the size of surviving plants although small, were positive.

These results support the observation that regardless of morphology, all cultivars were severely affected by drought (Brock 1988), but recovery was faster in the small-leaved Tahora than in the cultivars Huia, Pitau and Kopu with larger leaves and thicker stolons (Brock unpub data). Normally, $40-50 \%$ of stolon is buried during summer in most New Zealand pastures (Hay et al. 1987), which would provide some benefit to drought survival of large-leaved, thick-stolon white clover cultivars. The chief agent of burial is earthworm activity, which implies that regions with low earthworm populations and little winter burial may be disadvantaged, e.g. Taupo. Enhanced plant survival by shading treatment, particularly in numbers of plants, highlights the importance of maintaining adequate pasture cover, chiefly from companion grasses, to protect plants. Thus the defoliation 18 days into the drought period although typical of what could happen under rotational grazing, would be detrimental to white clover persistence as it would have removed pasture cover and protection from direct solar radiation. Changing management during the spring (set stocking) to increase pasture density and maintain cover would be a better alternative.

\section{Practicalimplications}

Differences in the morphology of white clover cultivars have little effect on plant survival under severe drought conditions. Maintenance of pasture cover through reduction in grazing pressure to reduce stress from solar radiation load appears to be the best option. Under rotational grazing, de-stocking and using conserved feed would be necessary, but the early recognition of impending drought makes this option difficult to implement. A better alternative would be to adopt a management practice during spring that ensures a high pasture (grass) density to provide protection for white clover pants, such as set stocking.

\section{ACKNOWLEDGEMENTS}

M.J.M. Hay of AgResearch Grasslands for help with experimental design and advice during the course of the experiment.

\section{REFERENCES}

Brock, J.L. 1988: Evaluation of New Zealand bred white clover cultivars under rotational grazing and set stocking with sheep. Proceedings of the New Zealand Grassland Association 49: 203-206.

Brock, J.L.; Hay, M.J.M.; Thomas, V.J.; Sedcole, J.R. 1988: Morphology of white clover(Trifolium repens L.) plants in pastures under intensive sheep grazing. Journal of agricultural science, Cambridge 11 I: 273-283.

Brock, J. L.; Hay, R. J. M. 1993. An ecological approach to forage management. Proceedings of the XVII International Grassland Congress: 837-842.

Caradus, J.R. 1986: World checklist of white clover varieties. New Zealand journal of experimental agriculture 14: 119-164.

Hay, M.J.M.; Brock, J.L.; Fletcher, R.H. 1983: Effect of sheep grazing management on distribution of white clover stolons amongst 3 horizontal strata in ryegrass/white clover swards. New Zealandjournal of experimental agriculture 11: 215-218.

Hay, M.J.M.; Chapman, D.F.; Hay, R.J.M.; Pennell, C.G.L.; Woods, P.W.; Fletcher, R.H.1987: Seasonal variation in the vertical distribution of white clover stolons in grazed swards. New Zealand journal of agricultural research 30: 1-8, 
Hay, M.J.M.; Brock, J.L.; Thomas, V.J., 1989: Density of Trifolium repens plants in mixed swards under intensive grazing by sheep. Journal of agricultural science, Cambridge 113: 81-86.

Turner, L.B. 1990: The extent and pattern of osmotic adjustment in white clover (Trifolium repens L.) during the development of water stress. Annals of botany 66: $721-727$.

Turner, L.B. 1991: The effect of water stress on the vegetative growth of white clover (Trifolium repens L.): Comparison of long-term water deficit and a short-term developing water stress. Journal of experimental botany 42: $3 \quad 1 \quad 1-3 \quad 16$.

Vartha, E.W.; Hoglund, J.H. 1983: What's the make up of a dryland pasture? Proceedings of the New Zealand Grassland Association 44: 204-210. 